\title{
A NOTE ON THE LIGHT-EMISSION OF SOME AMERICAN LAMPYRIDA.
}

BY F. ALEX. MC DERMOTT, WASHINGTON, D. C.

In connection with the collection of specimens for some work on physiologic light, I have had occasion to observe the modes of lightemission of some species of American Lampyridæ common in this neighbourhood (Washington, D. C:), and thought that some of these might be of interest. The species most common here, at least within the city limits, is Photinus pyralis Linn.; Photinus consanguineus Lec., Photinus scintillans Say, Photuris pennsylzanica Geer, and Lecontea (Pyractomena) angulata Say, were also observed. Each of these species appears to emit its light in a different and characteristic way--sometimes in several ways.

The insect whose light-emission is best known here is the Photinus pyralis. This is the insect which abounds in our parks during the summer, and with whose peculiar "dipping" flight as it flashes most of us Washingtonians are familiar. This dipping flight is indulged in by the male, apparently while seeking its male, and consists usually of a short downward flight, followed by a longer upward flight, during the whole of which the insect emits a continuous light, the whole phenomenon occupying from half a second to a second. The light appears to be at its maximum brilliancy during the turn at the lowest point of the flight, increasing rapidly on the descending flight, and decreasing on the ascending. At the completion of the flash the insect remains dark for some seconds, or perhaps minutes, and then repeats the operation, either near the same locality, or after a flight to some point usually not far from its starting point. Sometimes the light does not entirely die out immediately after the flash, but a phosphorescent glow is left shining for some seconds, sometimes till the next flash - and by this residual glow the insect may be trailed with ease at night. Later in the evening the insects fly higher, and then flash when flying straight, or, indeed, in any direction; the dipping flight appears to be indulged in only when near the earth. Occasionally they flash near the earth when flying in a curve the reverse of that described, that is, a rising flight followed by a descending one; rarely, also, they may be observed to twinkle, as will be described for the Photuris.

This description applies only to the male pyralis. The luminous organ of the male of this species occupies the entire ventral surface of the two abdominal segments next to the last, as well as a good portion, almost half, of the preceding segment. The luminous organ of the female occupies only a small spot, about a third of the ventral area, of the third

November, 1910 
abdominal segment from the end. Although with apparently as strong wings as the males, they are heavier bodied, especially when pregnant, and fly comparatively slowly and for short distances, and their organ gives much less light than that of the male, though of the same quality, greenishyellow. Both the male and female of this species have two small luminous points on the last abdominal segment; these points frequently present a continuous faint glow when the rest of the organ is dark, but they do not appear to be involved in the normal flash of the insect.

The larva of the pyralis is a narrow, sluggish glow-worm, and emits light from the ventral side of the next to the last abdominal segment. The lower side of the thoracic segments and the edges of the abdominal segments show the pink coloration characteristic of the thorax of the imago. In walking it pushes itself along with the end of the abdomen, as described below for the larval pennsylvanica; the pyralis larva, however, does not appear to have acquired the aquatic habits of the pennsylvanica, although it may be found in company with the latter glow-worm, in moist earth along the edge of roadways and paths.

After the pyralis, the most common Lampyrid here is the Photuris pennsyivanica Geer. This insect appears a little later in the evening than the pyralis, and may frequently be noticed flitting around trees and bushes just after sundown. It is usually easily distinguished from the pyralis by its different mode of light-emission, and the more greenish (or bluish) quality of its light. It is a much more active insect than the pyralis, with longer legs and a harder covering; both sexes are winged and equally active. In both sexes the luminous apparatus occupies the ventral sides of the two segments of the abdomen next to the last, and apparently a portion of the dorsal side also, since the light may be seen through the slight gap between the elytra when the insect is viewed from above. The female appears to give a slightly less intense light; at least, in mating, one insect is usually to be observed to be less brilliant than the other. The males are fighters, and on several occasions, when two or more have been imprisoned in a test-tube together, they have been known to kill one another, the insect killed being partially dismembered and the ventral portion of the thorax torn out.

The larvæ of Photuris pennsylvanica are broad, flat, sluggish glowworms, rather resembling the common wood-lice; they carry two small points of light on the next to the last segment of the abdomen, and when walking push themselves along with the end of the abdomen. About onethird of the apparent width of the larva consists of broad, translucent, 
horny plates, which extend outward from either side of each segment. These larvæ (pennsylvanica) appear to be semi-aquatic in habit; at this time of the year (early Sept.), while walking along the edge of Rock Creek, in Rock Creek Park, Washington, D. C., numerous points of greenish light, which glow slowly and then die out slowly, to glow again in a moment or so, may be seen at the very edge of the water; on investigation these proved to be the larval forms of the Photuris clinging to moist stones, weeds, etc., and presumably preying upon the smaller living things there. I noticed one quite remarkable sight; looking over a bridge which spans the creek just above a dam, one could see several of these points of light apparently on the surface of the water, and within a radius of about five feet, glowing and dying out again in their characleristic manner; upon closer observation there appeared to be at least a hundred of these larvæ thus apparently floating. The current here is slow, but perceptible, and as the mass of points of light did not change their position either with relation to each other or with the bridge, they must have been clinging to grasses or stones at the surface of the water. When compared at night in the same tube, the light of the larva of pennsylvanica is distinctly more greenish than that of the larva of pyralis.

The first time I saw the pennsylvanica in this neighbourhood, they were flitting around the tops of some rather high trees, the flight being in no particular direction. As seen there, they flashed with greater frequency than the pyralis ordinarily does; and the flash, instead of being a single prolonged emission, as in the latter insect, consisted of a series of several short, brilliant flashes, which may be best described as a "twinkling." This twinkling has often been observed since, and appears to be one of the methods of light-emission most commonly indulged in by this species.

Since this first observation, however, the pennsylvanica has been observed to emit light in several other characteristic ways. The most common of these, and probably the most common mode of light-emission of this insect, consists of a single prolonged flush, about as long in duration, and about as frequently repeated as the dipping flush of the pyralis, delivered while the insect is flitting around bushes and the branches of trees. The flash differs markedly from that of the pyratis. It begins as a faint glow, rapidly increasing in brilliancy, until it attains an intensity obviously much greater than that of the illumination of the commoner insect. It then ends suddenly, leaving an impression on the retina similar to, but of course much less intense than that produced by a sudden flish of lightning observed at night. As the maximum intensity of the light is 
approached the speed of flight appears to diminish, and as the final point is reached the insect flies very slowly in a small rising helix, or, if flying straight, may come to an almost complete stop. Occasionally the flash is followed by a residual phosphorescence, similar to that observed with the pyralis, and rather more rarely the flash is not ended suddenly, but allowed to fade out more gradually, in a manner resembling the normal flash of the pyralis.

Another natural mode of light-emission of this insect consists of a single, momentary bright flash, lasting only a small fraction of a second, and delivered without respect to location or manner of flight; these flashes are apparently isolated instances of the flashes emitted by the insect when in captivity, as will be described, or of the last natural mode of light-emission which I have noticed. This last method, which I have observed only three times, consists of a vertical drop or fall of several feet-about ten feet in each of the three cases noted-during the whole course of which the insect is flashing rapidly. On the third occasion on which I noticed this falling flight, the insect continued to flit around the weeds near which he had dropped, still flashing rapidly.

In captivity the pyralis soon loses its luminous propensity, and attains a quiet, slow.creeping condition, in which it gives no light, or only occasional flashes. The pennsyivanica, however, is very restless when in captivity, running rapidly around his prison, and flashing almost continuously at intervals of about a second, these flashes never reach the full brilliancy of the natural coruscations of the insect, but are still quite bright.

The males of Photinus consanguineus, P. scintillans and Lecontea angulata all emit their light in short, bright flashes, apparently without relation to their manuer of flight. The angulata emits two such flashes, separated by a fraction of a second's interval, followed by a longer interval before the next 1wo. The consanguineus usually emits a single flash, much shorter and more sudden than that of the pyralis, sometimes followed by a residual phosphorescence, similar to that of the pyralis; occasionally, too, I have seen them give a twinkling light, suggestive of the pennsylvanica. The males of both of these species were first captured under the impression that they were the pennsyluanica, only the light being observed before capture. In both of these species the luminous organ of the male is confined to the ventral surfaces of the two abdominal segments next to the last. I have not yet captured a living female of the consanguineus; the female of the angulata has an organ of irregular shape, situated on the ventral surfaces of the same segments as in the male; the 
light must be less intense than that of the male, but I have not observed them at night. In the cyanide killing-bottle the organ of the female augulata shines as four luminous points. The light-emission of the male scintillans is very similar to that of the pyralis, but shorter in duration, and not delivered during a dipping flight, but when flitting irregularly around bushes, etc. In appearance and location of the light-organ the male scintillans is a diminutive male pyralis, and from Watasés drawings. the female scintillans much resembles the female pyratis.

Dr. Frederick Knab (Can. EnT., I 905, Vol. 37, pp. 238-239) has mentioned the difference in quality between the light of Photinus scintillans and Photuris pennsylvanica, and Turner (Psyche, 1882 , Vol, 3, P. 309), has called attention to the similarities and differences between the light of Photinus pyralis, Photuris pennsylvanica and Pyrophorus noctilucus. Aside from the fact that the pennsylvanica is a considerably larger insect, and, therefore, witha larger luminous apparatus, there is certainly a distinct difference in the light. I have never submitted the light of scintillans to analysis with a spectroscope, but I have compared the light of pyralis, pennsylvanica and consanguineus with a small Schmidt \& Hæensch spectroscope, having an arbitrary numerical scale reading fron 0 in the red (the lower end of the visible spectrum) to 65 , the end of the visible violet, and on which the sodium D-line corresponds to No, ${ }_{3} 3$, and the calcium lines $\mathrm{H}_{1}$ and $\mathrm{H}_{2}$ to $5^{6.5}$ and 58.5 respectively. This little instrument resolved the light of the pyratis into a continuous band, extending from 5 to 25 of the scale, corresponding to the "structureless, unsymmetrical band" obtained by Ives and Coblentz (Bull. of the Bur. Standards, Wash, D. C., I9ro, Vol. 6 , pp. $\left.321-33^{6}\right)$, in their excellent work on the luminous efficiency of the firefly. The light emilted by the pennsylvanica showed a shorter spectrum, extending from 7 to 24 of the scale, and that of the consanguineus even shorter, extending from 7 to $\mathbf{2 2}$ of the scale. These were single observations, which I have unfortunately been unable to more than partially confirm, but the fact that the spectrum of the light emitted by the two latter species appears to be shorter in the red end than that of the pyralis, would seem to account for its more decided green tinge. The red light which Dr. Knab and Mr. Barber (Proc. Ent. Soc. Wash, I 908, Vol. 9, pp. $4 \mathrm{I}-43$ ) mention as being noted in tropical species of Phengodes, is not regarded by Dr. Coblentz as being due to absorption in the chitin, as it would be but poor economy to generate such an efficient light, and then absorb a portion of it before its passage from the generating organ. 
What the substance is that is burned to produce this light we do not know. A large number of chenicals and inixtures of chemicals have been found to give light under certain conditions, usually of oxidation. One of these (formaldehyde and pyrogallol, oxidized by strong hydrogen peroxid solution), investigated by Max Trautz (Zeitschrift f. physikal. Chemie, 1905, Vol. 53, pp. I-III), produced a light whose spectrum appears to roughly approximate that of the fire-fly.

In this connection I have found that the spectrum of the light produced on moistening with commercial three-per-cent. hydrogen peroxid solution, the ground luminous tissue of the pyralis, which has been dried in hydrogen over sulphuric acid, extends only from 9 to 15 of the scale of the spectroscope; that is, it lies mainly in the yellow and yeliow-orange portions of the spectrum.

Some as yet unfinished histologic studies indicate that the structure of the photogenic organs of Photinus pyralis and Photuris penusylvanica are approximately the same, and much as described by Townsend (American Naturalist, r 904 , Vol. 38 , pp. I 27 - 51 ), for Photinus marginellus.

The question naturally arises, "What is the purpose of the lightemission?" That this phenomenon has some relation to the sexual function is scarcely to be doubied. Just why this family should possess this power, while it is limited to occasional members of other families and of other orders of insects, that is, just what conditions of life and environment render it necessary as an adjunct to the sexual function, is not yet determined. Ehrenberg, in his extensive work, "Das Leuchten des Meeres" (Abhandl. d. k. Akad. d. Wissenschaften, Berlin, 1834-1836, pp. 4II-575), agrees that, while the explanation that the luminosity is an adjunct of the sexual function is acceptable for the Lampyrida and other bisexual forms, it will not hold for the hermaphroditic marine organisms that are luminous, while Watasé (Protoplasmic contractility and Phosphorescence, Biol. Lectures, Wood's Hole, 1898, pp. I 77-192) seems to leave one with the impression that he regards phosphorescence as a potential property of all protoplasm. I have no further explanation to offer in this connection, but the following chance observation may be of interest :

I was looking over a fence down a sloping field, a little later in the evening than the period of greatest activity on the part of the pyralis. There was no sign of luminosity nearby, though some distance away several males of the pyralis were flying about, One of these flew towards the fence, and then dropped downward, giving his characteristic dipping flash. Immediately the less intense lights of several pyralis females appeared in the nearby weeds, where their presence had theretofore not 
been suspected. Since observing this instance, several similar, but not so clearly defined cases, have been noticed. Barber's observations on Phengodes laticolits (Proc. Wash. Ent. Soc., Vol. 7, pp. 196-I 97), also point strongJy to the relation between luminosity and sexual function in that species.*

Both sexes of pyralis appear to be non-luminous during copulation, but flash if disturbed.

The phenomenon would be easier to understand if only the apterous or more sluggish females were brightly luminous, while the males, as in Phengodes laticollis, were non-luminous, or but slightly so. But in our two species most common here the male is either considerably brighter than the female or approximately equal to his mate in brilliancy. The luminosity of larva is also a litlle hard to comprehend, except as a developmental form of a rudimentary organ. Dubois has claimed that even the unfertilized eggs are luminous.

That the light has also a protective function is also readily surmised. I have heard of at least one boncifide instance, where the sudden flash of a fire-fly saved him from being made a portion of the evening meal of a chicken. Between the light which they give and the sticky exudation and unpleasant odour of most species, it seems hardly likely that they would prove a tempting morsel to insectivorous creatures. Toads, it is said, have been known to eat them.

There seems to have been some discussion, in times past, as to whether the light-emission of the various luminous forms was voluntary, or at least under the control of the organism. One argument that was advanced against the view that the phenomenon was under the control of the organism was that the light of the luminous tropical elaters, cucuyo, etc., was constant, and not intermittent. Anyone who studies the natural light-emission of the Lampyride can scarcely help but conclude that, except when they are subjected to some powerful excitement, such as mechanical, electrical or chemical stimuli external to the organism, the light-emission is entirely voluntary, and under the control of the will. Apparently the insects of the group Luciola emit a continuous twinkling, which has been stated to be synchronous with the respiratory movements of the abdomen, or with the circulatory impulses of the hemolymph; such synchronism may exist, but it would hardly seem to be proof that the lightemission was not under the control of the insect's will. The cucuyo, indeed, has been observed to vary the intensity of its light apparently entirely at will.

*I regret that in this connection I have not yet been able to secure a recent paper by Meissner, "Wie leuchten die Lampyrida?" in the Entomologische Wochenblatt, I9o7, Vol. 24, p. 6I. 